\section{Measurement of acoustic startle response in mice*}

\author{
CHARLES WILSON and PHILIP M. GROVES \\ University of Colorado, Boulder, Colorado 80302
}

Apparatus for measurement of acoustic startle response in mice is described. The technique utilizes a spring suspended lever, commercially available strain-gauge transducer, and polygraph. Individual startle responses are recorded as upward (flexion) and downward (extension) pen deflections, the force of either component being linearly related to the amplitude of the vertical pen deflections. The apparatus, with minor modifications, may be used to measure startle responses in larger rodents.

The acoustic startle response is a diffuse motor and autonomic reaction to sudden intense auditory stimuli (Landis \& Hunt, 1939). Most commonly, the major motor components include initial generalized flexion with subsequent extension. The startle response has been described for many species of animals, including rat (e.g., Prosser \& Hunter, 1936), cat (e.g., Forbes \& Sherrington, 1914), and human (e.g., Gogan, 1970). It has been of considerable research interest because of its utility in studying drive and emotional state (e.g., Brown, Kalish, \& Farber, 1951), the formation of conditioned responses (e.g., Szabo \& Kolta, 1967), and because, under appropriate conditions, it shows clear decrement (habituation) with repeated exposure to the auditory stimulus (e.g., Prosser \& Hunter, 1936). Although a great deal of research activity has been devoted to the acoustic startle response in rats, we are unaware of any previous reports dealing specifically with the acoustic startle response in mice.

The startle response has been measured typically using some variation of the "rat stabilimeter" devised by Mowrer, as described by Brown (1939). These devices most commonly consist of a postage stamp scale or similar spring suspension system, to which a small animal chamber is attached. The movement of the box is damped and transmitted to a mechanical recording mechanism. More recently, investigators have developed techniques in which the movement of the box is transduced into an electrical signal and recorded conveniently and accurately without complicated mechanical linkages. Some of these techniques include the induction of a current in a

* Supported in part by Grant MH 19515-01 from the National Institute of Mental Health. We wish to thank Bob Shoemaker and Richard Boyle for their skilled technical assistance. coil by movement of a magnet attached to the animal chamber (e.g. Hoffman \& Fleshler, 1964), or slight movement of a record-player stylus by displacement of the animal chamber (e.g., Anderson, Johnson, \& Kempton, 1969).

The startle response recording device that we describe here was designed to measure the acoustic startle response of mice but serves equally well with larger animals provided a suitable animal chamber is substituted. The apparatus is shown in Fig. 1. The animal chamber (A), made of Plexiglas and well vented with holes, is attached to a spring-loaded platform (B), hinged to a support stand $(\mathrm{C})$. The tension on the platform can be varied by simple adjustment of the spring (D). The movements of the platform are damped by a piston suspended in an oil-filled cylinder (E). The displacement force of the animal chamber is translated directly by a strain-gauge transducer (F; Grass Model FT .03C) held in place by a ringstand and clamp (G). The entire apparatus is housed in an acoustically insulated wooden box with speaker $(H)$, ventilation hole (I), and light (J) mounted in the back wall. The strain-gauge transducer is led to a conventional dc amplifier designed for that purpose (Grass Model 5P1) in an inkwriting polygraph (Grass Model 5). We have found that an adequate stimulus for eliciting the acoustic startle response in mice is a white noise burst (20-msec duration) above approximately $105 \mathrm{~dB}$ (re: 0.0002 dynes/ $\mathrm{cm}^{2}$ ), delivered from a white noise generator (e.g., Grayson-Stadler Model 901B) switched with an appropriate timer (e.g., Hunter Interval Cycler, Model 124S).

In our initial efforts to measure the acoustic startle of mice we encountered some difficulty with standard stabilimeter devices particularly in obtaining a good signal-to-noise ratio. The use of this damped suspension lever system coupled with a force transducer (for

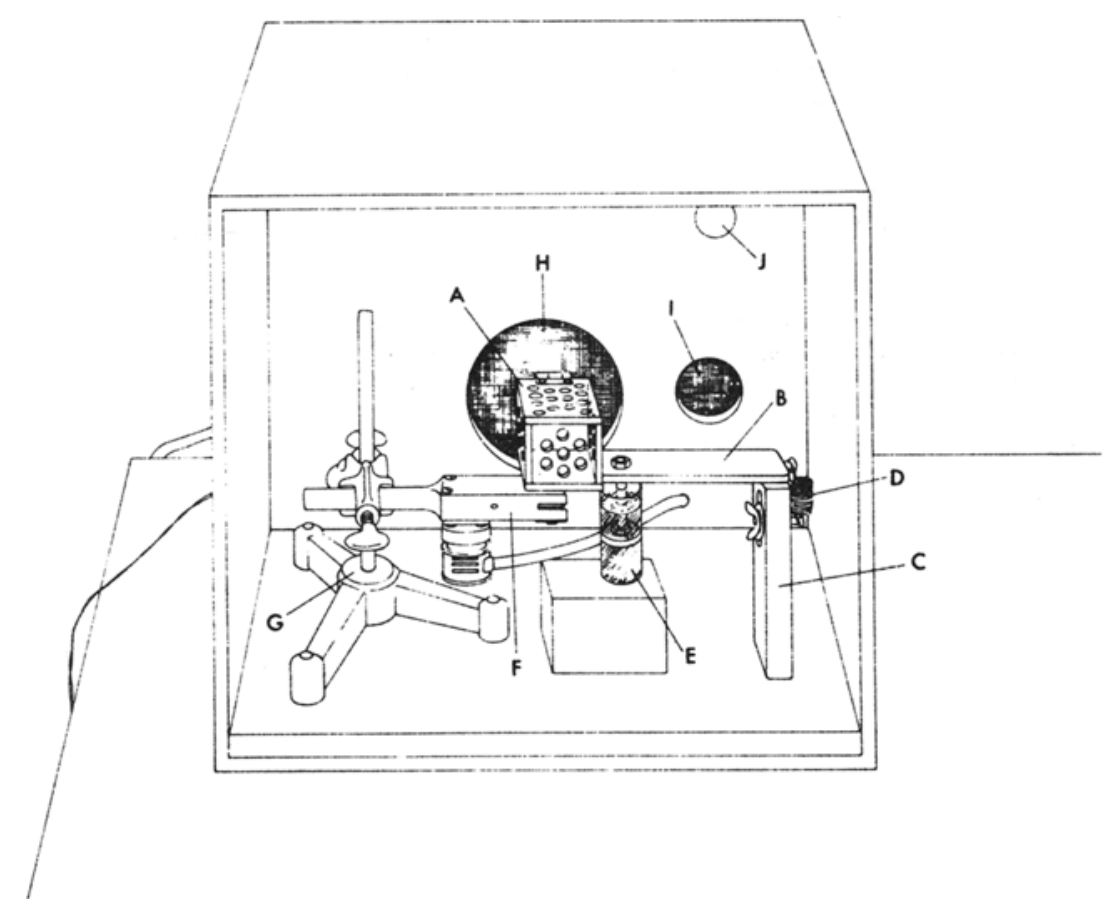

Fig. 1 Apparatus for measuring acoustic startle response of mice. Movement of the animal chamber is translated directly by a commercial strain-gauge transducer (F) and recorded by means of an ink-writing oscillograph. Operation and identification letters are described in detail in the text. 
$1-18$

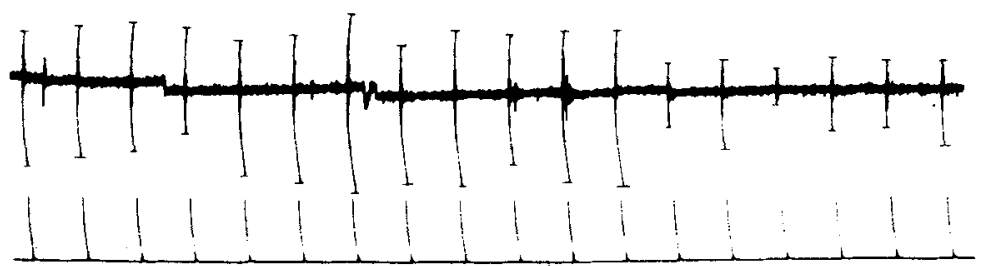

$101-118$


201-218
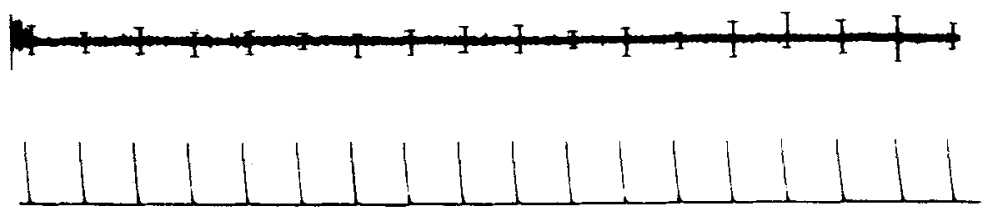

Fig. 2. Acoustic startle response as recorded on polygraph paper. Upper record in each case represents acoustic startle response (marked with horizontal bars), and lower record, the stimulus marker. The amplitude of the startle response is large during the initial presentations (1-18) of the stimulus (110-dB burst of white noise) but as the stimulus is repeated at 5-sec intervals startle response amplitude wanes (Trials $101-118$ and 201-218). Time between stimulus markers is $5 \mathrm{sec}$, and amplitude of stimulus marker is $5 \mathrm{~g}$.

mice a working force of from $2.0 \mathrm{mg}$ to $2.0 \mathrm{~kg}$ ) has provided reliable records of acoustic startle. Figure 2 illustrates data from the polygraph record of acoustic startle responses of a mouse and habituation with repetition of the acoustic stimulus (in this instance, a 110-dB burst of white noise, $20 \mathrm{msec}$ in duration delivered every $5 \mathrm{sec}$ ). Note that the initial responses to the white noise (1-18) are quite large. However, as the stimulus is repeated, the responses gradually wane in amplitude (101-118) and at the end of the series are quite small (201-218), providing evidence for marked habituation. The typical startle contains some amount of noise. In addition, we use a stimulus marker, ensuring accurate measurement of responses which might otherwise be obscured.

By changing animal boxes, the tension in the balancing spring, the working force of the strain-gauge, and the polygraph sensitivity, we have also obtained reliable records of acoustic startle in larger rodents (rats). The use of a force transducer has the advantages of its being commercially available, and its providing, in conjunction with appropriate amplifier and inkwriting oscillograph, a graphic record of startle, the amplitude of which is linearly related to force.

\section{REFERENCES}

ANDERSON, D. C., JOHNSON, D., \& KEMPTON, H. Second-order fear conditioning as revealed through augmentation of a startle response: Part $I$. Psychonomic Science, 1969, 16, 5-7.

BROWN, J. S., KALISH, H. J., \& FARBER. I. E. Conditioned fear as revealed by magnitude of startle response to an auditory stimulus. Journal of Experimental Psychology, 1951, 41, 317-328.

BROWN, J. S. A note on a temporal gradient of reinforcement. Journal of Experimental Psychology, 1939, 25, 221-227.

FORBES A \& SHERRINGTON, $c, s$. Acoustic reflexes in the decerebrate cat. American Journal of Physiology, 1914, $35,367-375$.

GOGAN, $P$. The startle and orienting reactions in man. A study of their characteristics and habituation. Brain Research, 1970, 18, 117-135.

HOFFMAN, $H, S$ FLESHLER, $M$, An apparatus for the measurement of the startle response in the rat. American Journal of Psychology, 1964, 77, 307-309.

LANDIS, C. \& HUNT, W. A. The startle pattern. 1939.

PROSSER, C. L., \& HUNTER, W. S. The extinction of startle responses and spinal reflexes in the white rat. American Journal of Physiology, 1936, 117 609-618.

SZABO, I., \& KOLTA, P. Transitory increase of the acoustic startle reaction during its habituation. Acta Physiologica Academiae Scientarum Hungaricae, 1967. 31, 51-56. 